\title{
Perancangan Dan Pengukuran Performansi Jaringan Fiber To The Home Dengan Teknologi Gigabit Passive Optical Network Menggunakan Aplikasi Optisystem Di Kelurahan Surau Gadang
}

\author{
Silvia Fitri ${ }^{1}$, Siska Aulia ${ }^{2}$, dan Aprinal Adila Asril ${ }^{3}$ \\ ${ }^{123}$ Jurusan Teknik Elektro, Politeknik Negeri Padang, Jl. Limau Manih Padang, 25164, \\ Indonesia \\ * email: silviafitri0124@gmail.com
}

\begin{abstract}
a Fiber To The Home (FTTH) network is designed in Surau Gadang Village where the area is designed and measured network performance where the standards used are in accordance with PT. ICON+. The procedures used in this design are positioning, gathering information, and designing using the Google Earth and OptiSystem applications. The results of the comparison between the OptiSystem measurements and measurements in the field obtained different attenuation results, where the results of measurements on the OptiSystem customers with the farthest distance resulted in an reception power of $-18.277 \mathrm{dBm}$ while for field measurements the customers with the furthest distance produced an reception power of $-18.52 \mathrm{dBm}$. The Rise Time Budget parameter obtained from the calculation is $0.029 \mathrm{~ns}$ which has met the feasibility standard, which is not more than 0.219 ns, while the Bit Error Rate value in the simulation is $8.11464 \times 10$ 33 which has met the feasibility standard is not more than 10-9. The value of Signal To Noise Ratio (SNR) is 50.044831 dB which also meets the minimum SNR standard of $21.5 \mathrm{~dB}$. From the calculation results and simulation results obtained values that still meet the feasibility standards of the Fiber To The Home network so that the design is feasible to be implemented.
\end{abstract}

Keywords: Fiber To The Home, Power Link Budget, Rise Time Budget, Bit Error Rate

\section{Pendahuluan}

Pada saat ini ketertarikan masyarakat akan teknologi informasi dan komunikasi cukup besar, sehingga kebutuhan layanan telekomunikasi tidak hanya telepon melainkan adanya akses internet yang membutuhkan bandwidth yang besar. Teknologi jaringan akses tembaga belum dapat mencukupi per mintaan pelanggan yang membutuhkan bandwidth dengan kapasitas yang besar serta berkecepatan tinggi sehingga perlu untuk melakukan peningkatan infrastruktur layanan dari jaringan akses tembaga menuju jaringan akses fiber sebagai media transmisinya, dalam meningkatkan kualitas layanan tersebut maka operator membuat infrastruktur menggunakan serat optik yang dikenal dengan jaringan Fiber To The Home (FTTH) dengan teknologi yang digunakan dikenal dengan nama Gigabit Passive Optical Network (GPON).[1]

Sistem komunikasi serat optik dengan cepat mampu bersaing menggantikan sistem-sistem lain dengan keunggulan yang dimilikinya yaitu memiliki bandwith yang besar, redaman transmisi kecil, ukuran kecil, kemudahan penambahan kapasitas, performansi yang lebih baik, tingkat ketersediaan yang tinggi dan jaringan transport yang handal. [2] Jaringan FTTH adalah suatu jaringan akses atau jaringan yang menghubungkan antara pusat layanan dengan peralatan pelanggan dengan menggunakan fiber optik. Teknologi yang digunakan dalam FTTH dikenal dengan Teknologi GPON adalah teknologi yang digunakan untuk mengatur trafik layanan pada jaringan FTTH, teknologi GPON mempunyai bit rate informasi yang lebih dari 1 Gigabit perdetik.

Perancangan jaringan serat optik dengan jenis FTTH menjadi salah satu solusi untuk menggelar jaringan cepat ke pelanggan yang membutuhkan. Dalam perancangan jaringan ini dibuat simulasi dan analisis dari perancangan kabel serat optik dari sentral menuju rumah pelanggan langsung untuk mendapatkan nilai-nilai parameter analisisnya. Pembangunan jaringan FTTH diperlukan perencanaan dan analisa yang dapat dimulai dengan melakukan survei wilayah dan membuat rancangan jaringan FTTH menggunakan aplikasi. Dalam perencanaan ini, maka diperlukan suatu perancangan gambar dan aplikasi yang mencakup wilayah pelanggan, jalur transmisi dan peletakan perangkat dengan menggunakan aplikasi Google Earth dan Optisystem untuk merancang pembangunan sistem komunikasi serat optik menggunakan komponen- 


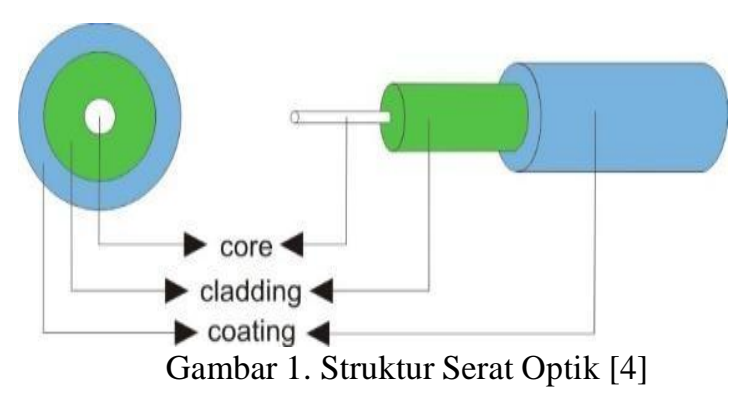

komponen yang sudah disediakan. Pada penelitian ini penulis akan membahas tentang perancangan jaringan FTTH beserta infrastruktur yang digunakan dan menganalisa performansi jaringan FTTH mulai dari sentral hingga ke pelanggan di kelurahan Surau Gadang dengan menggunakan denah letak perangkat dan mengumpulkan data-data real dari perusahaan yang di dapatkan melalui pengukuran langsung di lapangan.

Dalam penulisan ini penulis ingin menganalisa performansi jaringan FTTH yang menggunakan teknologi GPON, yaitu menganalisa performansi dari Optical Line Terminal (OLT) hingga ke user yang nantinya akan dirancang menggunakan aplikasi OptiSystem dan akan dilakukan simulasi untuk melihat hasil pengukuran pada perancangan tersebut, karena pada dasarnya FTTH adalah bagaimana cara mengirimkan informasi dari central hingga ke user, kemudian akan dilakukan analisa terhadap perbandingan hasil data real di lapangan dengan hasil rancangan menggunakan Optisystem. Berdasarkan hal tersebut penulis mengangkat judul penelitian "Perancangan dan Pengukuran Performasi Jaringan Fiber To The Home dengan Teknologi Gigabit Passive Optical Network Menggunakan Aplikasi OptiSystem di Kelurahan Surau Gadang", yang nantinya dapat digunakan sebagai pendukung proses pembelajaran baik praktek maupun teori untuk meningkatkan pemahaman mahasiswa dalam mempelajari sistem komunikasi serat optik.

\section{TINJAUAN PUSTAKA}

Teori dasar yang mendukung pembahasan ini sebagai berikut:

\section{A. Fiber optik}

Fiber optik suatu jenis kabel yang terbuat dari kaca atau plastik yang sangat halus, dan digunakan sebagai media transmisi karena dapat mentransmisi- kan sinyal cahaya dari suatu lokasi ke lokasi lainnya dengan kecepatan tinggi. Fiber Optik adalah media transmisi, karena dapat menstransmisikan sinyal cahaya dari satu lokasi ke lokasi lainnya dengan kecepatan tinggi dan kapasitas data yang besar. [3]

\section{B. Struktur Kabel Fiber Optik}

Karakteristik utama dari fiber optik adalah memiliki inti dari serat kaca dan memiliki beberapa lapisan yang tentunya tiap lapisan memiliki fungsi masing-masing. Pada gambar 1 merupakan struktur serat optik yang terdiri tiga bagian.

\section{Fiber to The Home}

Jaringan akses Fiber to The Home (FTTH) merupakan arsitektur teknologi fiber optik yang mengirimkan informasi dari provider hingga ke pengguna yang peletakan perangkat ONU berada di rumah-rumah pelanggan. Terminal pelanggan dihubungkan ke ONU dengan menggunakan kabel tembaga indoor dengan jarak yang cukup pendek. Perkembangan teknologi ini tidak terlepas dari kemajuan perkembangan teknologi serat optik yang dapat mengantikan penggunaan kabel konvensional dan juga didorong oleh keinginan untuk mendapatkan layanan yang dikenal dengan istilah Triple Play Services yaitu layanan akan akses internet yang ce- pat, suara (jaringan telepon, PSTN) dan video (TV Kabel) dalam satu infrastruktur pada unit pelanggan. [5].

\section{Komponen- Komponen Fiber To The Home} (FTTH)

Komponen-komponen jaringan Fiber To The Home (FTTH) terdiri dari :

1) Optical Line Terminal (OLT)

2) Optical Distribution Point (ODP)

3) Optical Distribution Cabinet (ODC)

4) Optical Network Termiination (ONT)

E. Parameter Kelayakan Hasil Rancangan Adapun PaKelayakan hasil rancangan Fiber To The Home (FTTH) adalah sebagai berikut:

\section{1) Power Link Budget}

Power Link Budget merupakan metode perhitungan dengan tujuan menghitung besaran daya yang diperlukan sehingga level daya yang diterima tidak kurang dari level daya minimum agar dapat dideteksi oleh penerima. Link power budget adalah perhitungan yang dilakukan untuk mengetahui batasan redaman total yang diizinkan antara daya output pemancar dan sensitivitas.

Terdapat 2 persamaan dalam perhitungan power link budget yaitu persamaan menghitung redaman total dan margin daya. Perhitungan power link budget dilakukan berdasarkan standarisasi ITU-T G.984, adapun persamaan redaman total sebagai berikut: [6] 
$a$ tot $=\mathrm{L} \cdot a$ serat $+\mathrm{Nc} \cdot a \mathrm{c}+\mathrm{Ns} \cdot a \mathrm{~s}+a \mathrm{Sp}$

Untuk menghitung margin daya digunakan per-

samaan berikut:

$\mathrm{M}=(\mathrm{Pt}-\mathrm{Pr})-a$ tot $-\mathrm{Ms}$

2) Rise time budget

Rise time budget merupakan metode untuk menentukan batasan dispersi suatu link serat optik. Metode ini sangat berguna untuk menganalisa sistem transmisi digital.

Untuk menghitung Rise time budget dapat dihitung dengan rumus:[7]

tsys $=(\mathrm{ttx} 2+\mathrm{tf} 2+\mathrm{trx} 2) 1 / 2$

\section{3) Signal to Noise Ratio (SNR)}

Signal to Noise Ratio (SNR) merupakan perbandingan daya sinyal terhadap noise pada satu titik yang sama. SNR merupakan parameter yang menampilkan berapa banyak noise atau gangguan yang terjadi pada suatu daya, data, atau pun informasiyang terkirim dari transmitter hingga sampai ke receiver.

\section{4) Bit Error Rate (BER)}

Bit Error Rate (BER) merupakan laju kesalahan bit yang terjadi dalam menstransmisikan sinyal digital. Sensitivitas merupakan daya optic minimum dari sinyal yang dating pada bt error rate yang dibutuhkan. BER untuk system komunikasi optik sebesar 10-9.

\subsection{Alur Perancangan}

Perancangan pada penelitian ini melewati beberapa proses untuk menyelesaikannya, hal tersebut bisa ditampilkan dalam diagram alur sebagaimana pada Gambar 2 berikut.

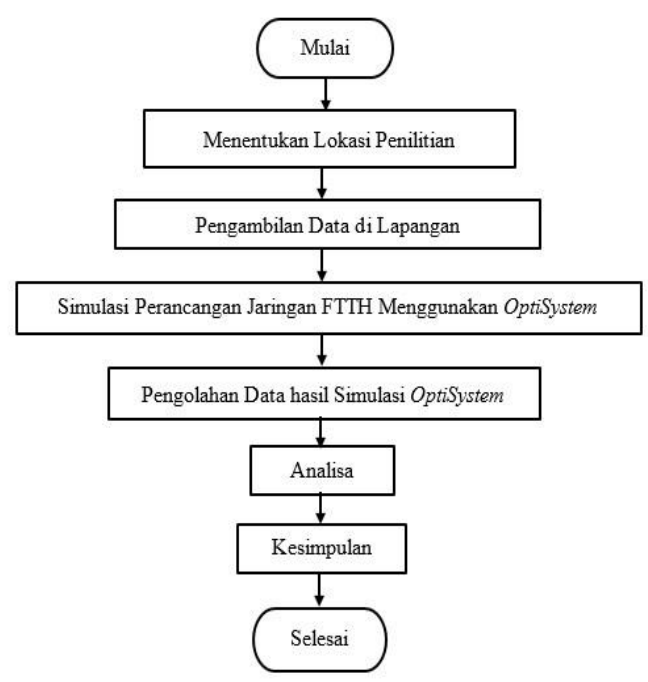

Gambar 2. Alur Perancangan Penelitian

\subsection{Penentuan Lokasi Perancangan}

Dalam menentukan lokasi hal yang dilakukan pertaman kali adalah mengirim surat perizinan untuk melakukan penelitian di PT. Indonesia Comnets Plus, setelah mendapatkan perizinan maka lokasi penelitian yang dapat ditentukan sesuai keputusan pihak PT. Indonesia Comnets Plus.

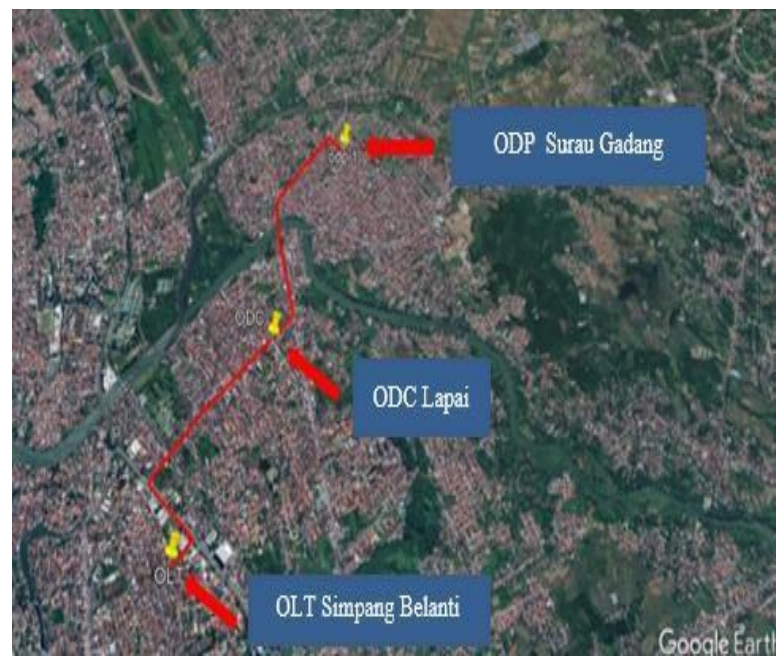

Gambar 3. Lokasi Perancangan Jaringan FTTH

\subsection{Pengambilan data di Lapangan}

Pengukuran data yang dibutuhkan yaitu denah OLT ke ONT yang digunakan dalam perancangan, setelah itu melakukan pengukuran untuk setiap perangkat.

\subsection{Simulasi Perancangan Jaringan FTTH Menggunakan OptiSystem}

Perancangan dimulai dari sisi sentral sampai dengan sisi pelanggan dengan menggunakan software OptiSystem, berdasarkan dari data di Lapangan.

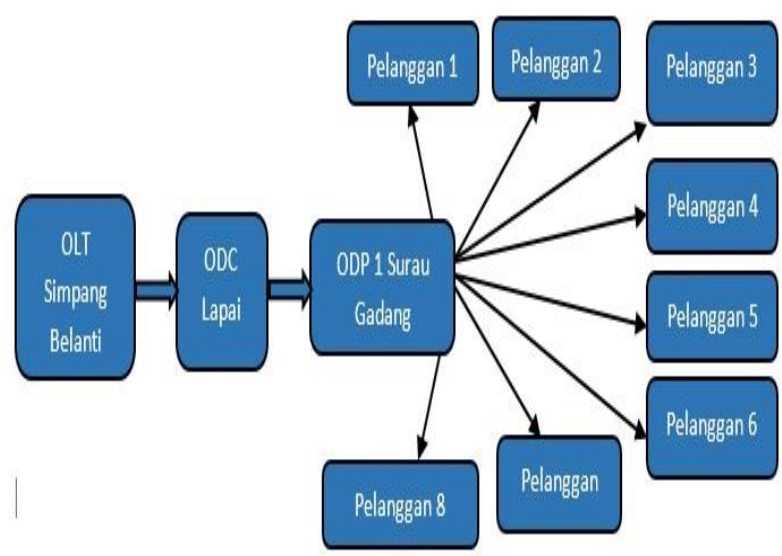

Gambar 4. Blok Diagram Rancangan Jaringan FTTH 
Gambar 4 merupakan diagram rancangan berdasarkan perancangan jaringan FTTH yang berada di lapangan. Hal ini digunakan untuk mengukur performansi sebuah jaringan FTTH. Jaringan FTTH yang dibangun di lapangan mulai dari OLT hingga ke rumah pelanggan seperti pada gambar 3, OLT berfungsi mengubah sinyal elektrik menjadi sinyal optik.

ODC merupakan suatu perangkat pasif yang berfungsi sebagai titik terminasi ujung kabel feeder dan pangkal kabel distribusi. Pada rancangan ini terdapat satu ODP dimana ODP tersebut terdiri dari 8 pelanggan. ODP berfungsi sebagai titik terminasi ujung kabel distribusi dan titik tambat awal, sebagai titik distribusi kabel distribusi menjadi beberapa saluran kabel drop, dan tempat penyambungan kabel distribusi dan tempat terminasi kabel drop.

ODP pada jaringan tersebut menggunakan kabel fiber optik bertype aerial, kabel aerial ini merupakan kabel yang digunakan pada instalasi ODP, dimana kabel aerial ditempatkan untuk kabel gantung yang berada diudara lepas. Pada ODP ini akan di keluarkan 8 output ke sisi user dengan panjang kabel yang berbeda-beda untuk melihat performansi jaringan yang dibangun, kabel yang digunakan dari ODP kerumah user menggunakan kabel indoor dimana kabel ini akan disambungkan dengan kabel aerial didalam ODP menggunakan splitter yang sudah dilengkapi dengan konektor.

Simulasi Perancangan Fiber To The Home (FTTH) Menggunakan Aplikasi Optisystem Hal yang terlebih dahulu dilakukan sebelum melakukan perancangan Fiber To The Home (FTTH) menggunakan Optisystem yaitu menentukan spesifikasi jaringan Fiber To The Home (FTTH) yang diatur pada layout Optisystem. Adapun spesifikasi perangkat yang digunakan pada perancangan ini antara lain :

Tabel 1. Perangkat dan Komponen Perancangan Jaringan FTTH Berdasarkan data Lapangan

\begin{tabular}{clc}
\hline No. & Perangkat/Komponen & Jumlah \\
\hline 1 & Transmiter & $1 \mathrm{pcs}$ \\
2 & $\begin{array}{l}\text { Power Splitter/Passive } \\
\text { Splitter 1:8 }\end{array}$ & $1 \mathrm{pcs}$ \\
3 & Power Splitter/Passive & $1 \mathrm{pcs}$ \\
& Splitter 1:4 & \\
4 & Kabel Fiber Optik (Aerial) & $4200 \mathrm{~m}$ \\
5 & Konektor & $12 \mathrm{pcs}$ \\
6 & Receiver & $8 \mathrm{pcs}$ \\
7 & Kabel Fiber Optik (Indoor) & $407 \mathrm{~m}$ \\
8 & Optical Distribution Point & $1 \mathrm{pcs}$ \\
\hline
\end{tabular}

Tabel 2. Parameter Perancangan Jaringan FTTH dengan OptiSystem

\begin{tabular}{cll}
\hline No. & \multicolumn{1}{c}{ Parameter } & \multicolumn{1}{c}{ Nilai } \\
\hline 1 & Bit Rate (BR) & $2.4 \mathrm{Gbps}$ \\
2 & Sensitivity Receiver & $-28 \mathrm{db}$ \\
3 & Wavelenght (Downlink) & $1490 \mathrm{~m}$ \\
4 & Optical Transmit Power & $4 \mathrm{dBm}$ \\
5 & Rise Time (OLT/ONT) & $0.02083 \mathrm{~ns}$ \\
6 & Connector Fiber Optik & $0.4 \mathrm{db} / \mathrm{km}$ \\
& indoor & 16.75 \\
7 & Dispersi Material Optik & $\mathrm{ps} / \mathrm{nm} / \mathrm{km}$ \\
& & $1 \mathrm{~nm}$ \\
8 & Lebar Spektrum & $0.2 \mathrm{dbm}$ \\
9 & Connector Loss & $0.2 \mathrm{db} / \mathrm{km}$ \\
10 & Connector Fiber Optik & $\mathrm{NRZ}$ \\
\multirow{2}{*}{11} & aerial & Tipe Modulasi
\end{tabular}

Gambar 5 berikut merupakan hasil rancangan Fiber To The Home (FTTH) menggunakan aplikasi OptiSistem

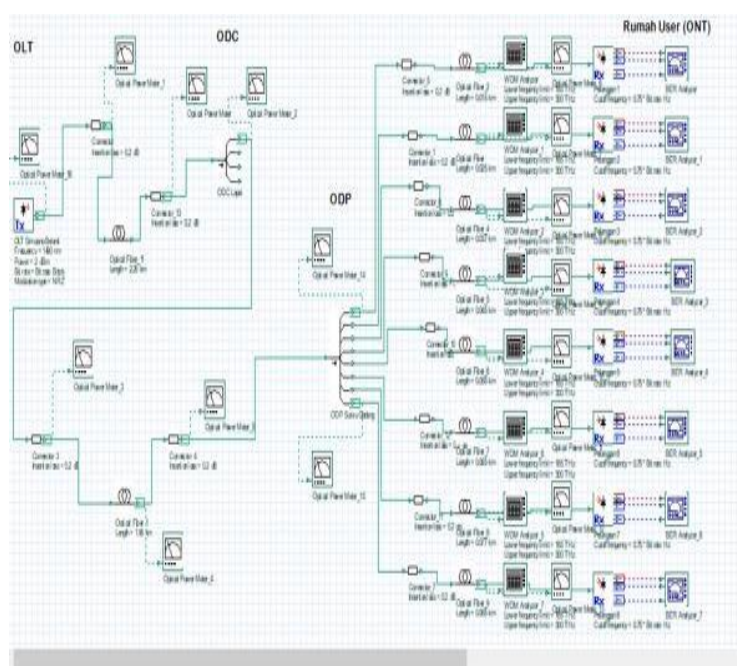

Gambar 5. Hasil Rancangan Menggunakan OptiSistem

\subsection{Pengolahan Data Hasil Simulasi}

Pengolahan Data Dari hasil simulasi maka didapatkan data berupa nilai daya input dan daya output pada setiap perangkat yang diukur menggunakan Optical Power Meter (OPM), data nilai Optical Signail to Noise Ratio (SNR) yang di ukur menggunakan WDM Analyzer dan nilai Bit Error Rate (BER) yang diukur menggunakan BER Analyzer. Kemudian dari metode perhitungan akan didapatkan nilai Power Link Budget, dan Rise Time Budget. 


\subsection{Analisa, Penarikan Kesimpulan dan Pembuatan} Laporan

Dari data hasil simulasi dan data hasil perhitungan maka kan dilakukan analisa dan ditarik kesimpulan apakah hasil rancangan sudah memnuhi standar kelayakan Fiber To The Home (FTTH).

\section{HASIL DAN PEMBAHASAN}

Setelah dilakukan pemetaan pada google earth maka didapatkan jarak dari OLT hingga ke pelanggan adalah sebagai berikut :

Tabel 3. Jarak dari ODP ke User

\begin{tabular}{ccc}
\hline No. & Titik Pengukuran & Jarak \\
\hline 1 & Pelanggan 01 & $0.015 \mathrm{Km}$ \\
2 & Pelanggan 02 & $0.025 \mathrm{Km}$ \\
3 & Pelanggan 03 & $0.037 \mathrm{Km}$ \\
4 & Pelanggan 04 & $0.045 \mathrm{Km}$ \\
5 & Pelanggan 05 & $0.058 \mathrm{Km}$ \\
6 & Pelanggan 06 & $0.065 \mathrm{Km}$ \\
7 & Pelanggan 07 & $0.077 \mathrm{Km}$ \\
8 & Pelanggan 08 & $0.085 \mathrm{Km}$ \\
\hline
\end{tabular}

\subsection{Hasil Simulasi}

Berikut merupakan hasil simulasi menggunakan aplikasi optisystem :

Tabel 4. Hasil Pengukuran Daya Terima OptiSystem

\begin{tabular}{lcc}
\hline Titik Ukur & $\mathrm{dBm}$ & $\mathrm{mW}$ \\
\hline Pelanggan 01 & -18.250 & 0.014963 \\
Pelanggan 02 & -18.254 & 0.014949 \\
Pelanggan 03 & -18.259 & 0.014932 \\
Pelanggan 04 & -18.262 & 0.014922 \\
Pelanggan 05 & -18.267 & 0.014903 \\
Pelanggan 06 & -18.270 & 0.014895 \\
Pelanggan 07 & -18.275 & 0.014878 \\
Pelanggan 08 & -18.277 & 0.014867 \\
\hline
\end{tabular}

Tabel 5. Hasil Perhitungan Power Link Budget

\begin{tabular}{lcc}
\hline \multicolumn{1}{c}{ Titik Ukur } & $\mathrm{dBm}$ & $\mathrm{mW}$ \\
\hline Pelanggan 01 & -18.595 & 0.013819 \\
Pelanggan 02 & -18.597 & 0.013813 \\
Pelanggan 03 & -18.599 & 0.013807 \\
Pelanggan 04 & -18.601 & 0.013800 \\
Pelanggan 05 & -18.603 & 0.013794 \\
Pelanggan 06 & -18.605 & 0.013787 \\
Pelanggan 07 & -18.607 & 0.013781 \\
Pelanggan 08 & -18.609 & 0.013775 \\
\hline
\end{tabular}

Tabel 6. Hasil Pengukuran Signal to Noise Ratio (SNR)

\begin{tabular}{lc}
\hline \multicolumn{1}{c}{ Titik Pengukuran } & SNR \\
\hline Pelanggan 01 & $50.047447 \mathrm{~dB}$ \\
Pelanggan 02 & $50.047446 \mathrm{~dB}$ \\
Pelanggan 03 & $50.047445 \mathrm{~dB}$ \\
Pelanggan 04 & $50.047445 \mathrm{~dB}$ \\
Pelanggan 05 & $50.047444 \mathrm{~dB}$ \\
Pelanggan 06 & $50.047443 \mathrm{~dB}$ \\
Pelanggan 07 & $50.047443 \mathrm{~dB}$ \\
Pelanggan 08 & $50.047442 \mathrm{~dB}$ \\
\hline
\end{tabular}

Tabel 7. Hasil Pengukuran Bit Eror Ratio (BER)

\begin{tabular}{lc}
\hline Titik Pengukuran & BER \\
\hline Pelanggan 01 & $2.47433 \times 10^{-88}$ \\
Pelanggan 02 & $1.64125 \times 10^{-102}$ \\
Pelanggan 03 & $1.18163 \times 10^{77}$ \\
Pelanggan 04 & $7.1354 \times 10^{-96}$ \\
Pelanggan 05 & $1.56491 \times 10^{-86}$ \\
Pelanggan 06 & $3.29914 \times 10^{-101}$ \\
Pelanggan 07 & $2.04193 \times 10^{-89}$ \\
Pelanggan 08 & $3.26053 \times 10^{87}$ \\
\hline
\end{tabular}

Tabel 8. Hasil Perhitungan Rise Time Fiber Optik

\begin{tabular}{lc}
\hline \multicolumn{1}{c}{ Titik Ukur } & $\begin{array}{c}\text { Rise Time Fiber } \\
\text { Optik }\end{array}$ \\
\hline Pelanggan 01 & $0.004984536502 \mathrm{~ns}$ \\
Pelanggan 02 & $0.005008215977 \mathrm{~ns}$ \\
Pelanggan 03 & $0.005036705415 \mathrm{~ns}$ \\
Pelanggan 04 & $0.005055743264 \mathrm{~ns}$ \\
Pelanggan 05 & $0.005086756362 \mathrm{~ns}$ \\
Pelanggan 06 & $0.005103495002 \mathrm{~ns}$ \\
Pelanggan 07 & $0.00513225378 \mathrm{~ns}$ \\
Pelanggan 08 & $0.005151471189 \mathrm{~ns}$ \\
\hline
\end{tabular}

\subsection{Pembahasan}

Pembahasan ini dimulai dari hasil simulasi nilai daya terima hingga pelanggan, data yang akan dibahas yaitu dengan mengambill sampel pelanggan dengan jarak terjauh karena apabila pelanggan dengan jarak terjauh sudah memenuhi standar kelayakan maka user lainya juga akan memenuhi standar kelayakan perancangan jaringan FTTH dimana pelanggan dengan jarak terjauh yaitu pada pelanggan 8 .

Perancangan jaringan FTTH dengan tekonlogi GPON menggunakan perangkat mulai dari OLT, ODC, ODP, hingga ONT, dimana perangkat tersebut harus memiliki spesifikasi yang memenuhi standar arsitektur teknologi GPON. Dalam menghitung 
performansi suatu jaringan FTTH dilakukan dengan menghitung parameter link power budget, rise time budget, signal to noise ratio dan bit error rate.

Parameter Rise Time Budget didapatkan dari perhitungan ialah $0.029 \mathrm{~ns}$, sedangkan nilai Bit Error Rate pada simulasi ialah $1.56491 \times 10^{-86}$ yang sudah memenuhi standar kelayakan yaitu tidak lebih dari $10^{-9}$. Nilai SNR merupakan $50.047442 \mathrm{~dB}$ juga telah memenuhi standar minimal SNR yaitu $21.5 \mathrm{~dB}$. Berdasarkan hasil perbandingan antara pengukuran OptiSystem dan pengukuran di lapangan didapatkan hasil redaman yang berbeda, dimana daya input yang diberikan sebesar 4 $\mathrm{dBm}$, hasil pengukuran pada OptiSystem pelanggan dengan jarak terjauh menghasilkan daya terima sebesar 18.277 dBm sedangkan pengukuran dilapangan pelanggan jarak terjauh menghasilkan daya masukan sebesar $-18.52 \mathrm{dBm}$.

\section{KESIMPULAN}

Perhitungan performansi suatu jaringan FTTH dilakukan dengan menghitung parameter link power budget, rise time budget, signal to noise ratio dan bit error rate. Dari data yang di dapatkan berdasarkan hasil simulasi optisystem dan hasil perhitungan dapat disimpulkan bahwa rancangan jaringan Fiber To The Home (FTTH) di Kelurahan Surau Gadang merupakan rancangan yang layak untuk diimplementasikan dan dijadikan acuan pembangunan jaringan Fiber To The Home (FTTH).

\section{REFERENSI}

[1] Sari, Intan Permata. 2015. Analisis Pengujian Implementasi Perangkat Fiber To The Home (FTTH) Dengan Optisystem Pada Link Sto Gegerkalong Ke Setra Duta Bandung. Jurnal Elektro Telkom University.

[2] Umaternate Iswan, Saifuddin M. Zen, dkk. 2016. Sistem Penyambungan dan Pengukuran Kabel Fiber Optik Menggunakan Optical Time Domain Reflectometer (OTDR) Pada PT. Telkom Kandatel Ternate. Jurnal Teknik Elektro Fakultas Teknik Universitas Khairun Ternate.

[3] Mukhlisin, Zulfikar Nur. 2021. Analisa Redaman Fiber Optic Pada Pemasangan Digitalisasi Spbu Pertamina Oleh PT. Telkom Witel Semarang Dengan Power Link Budget. Jurnal Teknik Elektro Fakultas Teknik Universitas Semarang

[4] Asril, Aprinal Adila. 2016. Sistem Komunikasi Serat Optik. Padang: Politeknik Negeri Padang.

[5] Alfarizi, Muhammad et al. 2015. Pembuatan De-sain Jaringan Fiber To The Home (FTTH) Pada Perumahan Buah Batu Square Ban- dung. Jurnal Penelitian Telkom University

[6] Figuerola et all. (2002). Fiber to The Home Tec nologies. New York: Springer Science+Business Media, LLC.

[7] Keiser, Gerd. 2003. Optical Fiber Communications. Singapore: McGraw-Hill Interna- tional Edition.. 